\title{
Threshold accepting optimization of road vaults and rectangular hollow bridge piers
}

\author{
A. Carbonell, F. Martinez, V. Yepes, A. Hospitaler \\ \& F. Gonzalez-Vidosa \\ School of Civil Engineering, Universidad Politécnica Valencia, Spain
}

\begin{abstract}
This paper deals with the economic optimization of reinforced concrete road vaults and with the optimization of rectangular hollow section bridge piers typically used in road construction. It shows the efficiency of a heuristic optimization by the threshold accepting algorithm. The evaluation of solutions follows the Spanish Code for structural concrete. Design loads are in accordance to the national IAP Code for road bridges. The algorithm is firstly applied to a RC hydraulic vault of $4.00 \mathrm{~m}$ of horizontal span and $800 \mathrm{~m}$ of length. This example has 23 discrete design variables, 3 geometrical, 3 of materials and 17 of reinforcement. Stress resultants and envelopes of vault structures are computed by an internal matrix method program. Best results amount to 958 euros $/ \mathrm{m}$ and they indicate savings of about $8 \%$ with respect to the prior real design office calculations. The second structure analysed is a $24 \mathrm{~m} \mathrm{RC}$ vertical height bridge pier of hollow rectangular cross-section, which supports the main span of a prestressed concrete road bridge of 60-90-60 meters of longitudinal spans. This example has 95 discrete variables, 15 geometrical, 7 types of concrete and 73 types of reinforcement bars of fixed length. The evaluation module includes the limit states that are commonly checked in design: flexure, shear, deflections, buckling, etc. Results indicate savings of about $30 \%$ with respect to the design based on the experience of the bridge designers. Finally, results indicate that heuristic optimization is a forthcoming option for improving the design costs of real RC structures.
\end{abstract}

Keywords: economic optimization, heuristics, concrete structures, structural design. 


\section{Introduction}

The search for efficient designs is as old as engineers. The traditional design of concrete structures aims at producing safe structures that sustain the loads and deformations, as well as the durability conditions of their intended life [1]. Also traditionally, designs have been usually based on the prior experience of the structural engineer, which has derived in a number of rules of thumb about crosssection dimensions and material grades based on sanctioned common practice. Once the structure is defined according to experience, it follows the analysis of stress resultants and the computation of passive and active reinforcement that satisfy the limit states prescribed by concrete codes. Should the dimensions or material grades be insufficient, the structure is redefined on a trial and error basis. Such process leads to safe designs, but the economy and constructability of the concrete structures are, therefore, very much linked to the experience of the structural designer. Alternatively, modern computational techniques of optimization offer another approach to the design of structures. In this sense, artificial intelligence has dealt, since its appearance in the mid-fifties, with a variety of fields that include the optimization of constrained problems. And basically, the design of concrete structures is a problem of selection of design variables subject to structural constraints for which artificial intelligence is very much suited. Design variables include material grades, cross section dimensions and reinforcement.

Optimization methods deal with the minimization of the objective function, which is usually the cost or the weight of the structure. In addition, multiobjective optimization algorithms offer a range of possibilities about the study of two or several conflicting objectives. As regards concrete structures, there have been little applications when compared to steel structures [2]. In general terms, the methods of structural optimization may be classified into two broad groups: exact methods and heuristic methods. The exact methods are the traditional approach. They are usually based on the calculation of optimal solutions following iterative techniques of linear programming [3,4]. The second main group are the heuristic methods, whose recent development is linked to the evolution of artificial intelligence procedures. This group includes a broad number of search algorithms [5-8], such as genetic algorithms, simulated annealing, threshold accepting, tabu search, ant colonies, etc. These methods have been successful in areas different to structural engineering [9]. They consist of simple algorithms, but require a great computational effort, since they include a large number of iterations in which the objective function is evaluated and the structural constraints are checked. Among the first works of heuristic optimization applied to steel structures, the contributions of Jenkins [10] and of Rajeev and Krishnamoorthy [11] in 1991-1992 are to be mentioned. Both authors applied genetic algorithms to the optimization of the weight of steel structures. As regards RC structures, early applications in 1997 include the work of Coello et al [12], who applied genetic algorithms to the economic optimization of RC beams. Recently, there have been a number of RC applications [13-20], which optimize RC beams and building frames by genetic 
algorithms. And also recently, our research group has applied simulated annealing and threshold acceptance to the optimization of walls, portal and box road frames and building framed structures [21-25].

The structures object of this work are road vaults and rectangular hollow section bridge piers which are usually built of $\mathrm{RC}$ in road construction. Road vaults are used with spans between 3.00 and $15.00 \mathrm{~m}$ for solving the intersection of transverse hydraulic or traffic courses with the main upper road. Road vaults are specially prescribed when there is a high earth cover and when the length of intersection is long, e.g. several hundred meters. The depth of the vault is typically designed between 0.20 and $0.75 \mathrm{~m}$ depending on the earth cover and the horizontal span. Vaults are calculated to sustain the traffic and earth loads prescribed by the codes and have to satisfy all the limit states required as an RC structure. As regards rectangular hollow piers, they are typically constructed for prestressed concrete viaducts with heights above the terrain of more than $20 \mathrm{~m}$. The thicknesses of the walls are between 0.25 to 0.50 m. Rectangular piers are calculated to sustain the vertical and horizontal loads transferred by the viaduct and, again, they have to satisfy all the limit states required as an RC structure. The method followed in this work has consisted first in the development of evaluation computer modules where dimensions, materials and steel reinforcement have been taken as variables. These modules compute the cost of a solution and check all the relevant limit states. Threshold accepting is then used to search the solution space.

\section{Threshold accepting optimization procedure}

The problem of structural concrete optimization that is put forward in the present work consists of an economic optimization. It deals with the minimization of the objective function $\mathrm{F}$ of expression (1), satisfying also the constraints of expressions (2).

$$
\begin{gathered}
F\left(x_{1}, x_{2}, \ldots, x_{n}\right)=\sum_{i=1, r} p_{i} * m_{i}\left(x_{1}, x_{2}, \ldots, x_{n}\right) \\
g_{j}\left(x_{1}, x_{2}, \ldots, x_{n}\right) \leq 0
\end{gathered}
$$

Note that the objective function in expression (1) is the sum of unit prizes multiplied by the measurements of construction units (concrete, steel, formwork, etc). And that the constraints in expression (2) are all the service and ultimate limit states that the structure has to satisfy. Unit prizes considered are given in Table 1.

The search method used in this work is the threshold accepting (TA henceforth), that was originally proposed by Dueck and Scheuer [26]. The algorithm starts with an initial randomly generated working solution, $\mathrm{P}_{\mathrm{o}}$, and an initial high threshold value for accepting solutions. TA then changes the solution by a move. A move is a small random variation up or down to the values of some of the variables that define the current solution. Given a current solution, 
a move is applied and, hence, a new solution is obtained. The new current solution, $\mathrm{P}_{1}$, is accepted if it has a lower cost or when the cost increment is smaller than the current threshold value. The current solution is checked against structural constraints and if it is feasible, it is adopted as the new working solution $\mathrm{P}_{\mathrm{o}}$. The initial threshold is reduced geometrically and gradually by means of a reducing coefficient. A number of iterations at each threshold step are performed in the same way as for Markov chains of the simulated annealing method [27]. TA method is capable of surpassing local optima and gradually converges as the threshold value reduces to zero. The method requires calibration of the initial threshold, of the length of the cycle chains and of the threshold reducing coefficient. Adopted values for the two examples of this work will be given below. The initial threshold value was adjusted following the method proposed by Medina [28], which consists in choosing an initial value and checking whether the percentage of acceptances of higher cost solutions is between for instance $10-30 \%$. If the percentage is greater than $30 \%$, the initial threshold is halved; and if it is smaller than $10 \%$, the initial threshold is doubled. Computer runs were performed 9 times so as to obtain minimum, mean and standard deviation of the random results.

Table 1: $\quad$ Basic prizes of the cost function of the reported structures.

\begin{tabular}{|l|r|r|}
\hline \multicolumn{1}{|c|}{ Unit } & $\begin{array}{r}\text { Cost case } \\
\text { study 1 }(€)\end{array}$ & $\begin{array}{c}\text { Cost case } \\
\text { study 2 }(€)\end{array}$ \\
\hline kg of steel (B-500S) & 1.00 & 0.63 \\
\hline $\mathrm{m}^{2}$ of foundation formwork & 9.02 & 18.00 \\
\hline $\mathrm{m}^{2}$ of walls formwork & 12.62 & 48.19 \\
\hline $\mathrm{m}^{2}$ of upper vault formwork & 21.04 & $\mathrm{NA}$ \\
\hline $\mathrm{m}^{3}$ of vault scaffolding & 10.82 & $\mathrm{NA}$ \\
\hline $\mathrm{m}^{3}$ of lower slab concrete (labour) & 3.61 & 5.41 \\
\hline $\mathrm{m}^{3}$ of wall concrete (labour) & 5.41 & 9.02 \\
\hline $\mathrm{m}^{3}$ of upper vault concrete (labour) & 4.51 & $\mathrm{NA}$ \\
\hline $\mathrm{m}^{3}$ of concrete pump rent & 4.82 & 6.01 \\
\hline $\mathrm{m}^{3}$ of concrete HA-25 & 43.72 & 45.24 \\
\hline $\mathrm{m}^{3}$ of concrete HA-30 & 46.58 & 49.38 \\
\hline $\mathrm{m}^{3}$ of concrete HA-35 & 49.43 & 53.90 \\
\hline $\mathrm{m}^{3}$ of concrete HA-40 & 52.29 & 59.00 \\
\hline $\mathrm{m}^{3}$ of concrete HA-45 & 55.14 & 63.80 \\
\hline $\mathrm{m}^{3}$ of concrete HA-50 & 58.00 & 68.61 \\
\hline $\mathrm{m}^{3}$ of earth removal & 3.01 & 3.01 \\
\hline $\mathrm{m}^{3}$ of earth fill-in & 4.81 & 4.81 \\
\hline
\end{tabular}

\section{Case study 1: road vaults}

The first example studied relates to RC vaults used in road construction [29]. The analysis includes 23 design variables. Figure 1 shows the 17 variables considered in this analysis for the reinforcement. Variables include 3 geometrical 
values: the depth of the vault, the depth of the lateral walls and the depth of the bottom foundation slab; 3 different grades of concrete for the 3 types of elements; and 17 types of reinforcement bars following a standard setup. All variables are discrete in this analysis. The total number of parameters is 24 , the most important of which are the horizontal free span which is twice the radius of the vault, the vertical height of the lateral walls, the earth cover, the stiffness modulus of the foundation and the partial coefficients of safety. Structural constraints considered followed standard provisions for Spanish design of this type of structure [30,31], that include checks of the service and ultimate limit states of flexure and shear for the stress envelopes due to the traffic loads and the earth fill. Traffic loads considered are a uniform distributed load of $4 \mathrm{kN} / \mathrm{m}^{2}$ and a heavy vehicle of $600 \mathrm{kN}$. Stress resultants and reactions were calculated by an internal finite element program using a 2-D mesh with 40 bars and 40 sections (out of plane bending moments had to be assumed as a practical one fifth proportion of in plane bending moments). Deflections were limited to $1 / 250$ of the free span for the quasi-permanent combination. Fatigue of concrete and steel was not considered since this ultimate limit state is rarely checked in road structures.

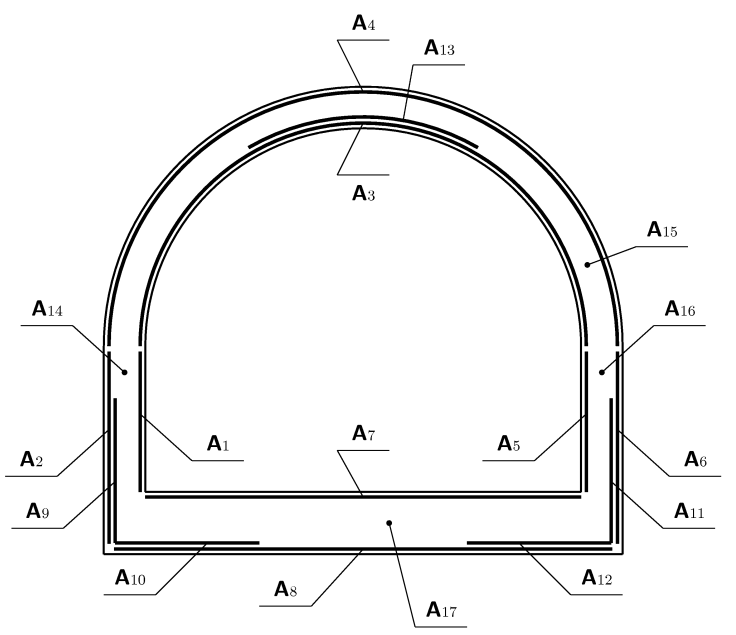

Figure 1: $\quad$ Variables of the RC vaults for case study 1.

The TA algorithm was programmed in Fortran 77. Typical runs were 9 minutes in an Intel Pentium IV processor of $2.60 \mathrm{GHz}$. The calibration of thresholds parameters amounted about 72 hours running of a heuristic procedure whose objective was to achieve minimum cost. In this case, the calibration recommended chains of 1000 iterations and a reducing coefficient of 0.75 , the total amount of iterations being about 70000. The most efficient move found consisted of random variation of up to 4 of the 23 variables of the problem. 
Table 2 details the main results of the TA analysis for a road hydraulic vault of $800 \mathrm{~m}$ and $4.00 \mathrm{~m}$ of horizontal free span, $1.40 \mathrm{~m}$ of vertical height of the lateral walls and $7.00 \mathrm{~m}$ of earth cover (additional parameters are $10 \mathrm{MN} / \mathrm{m}^{3}$ of stiffness modulus of the foundation; specific weight of the fill of $20 \mathrm{kN} / \mathrm{m}^{3} ; 30$ degrees internal friction angle of the fill; partial safety coefficients of 1.60 for permanent loading and life loading; and 1.50-1.15 for concrete-steel as materials). The depth of the top vault is only $0.20 \mathrm{~m}$ for the $4.00 \mathrm{~m}$ span, which means a slender span/depth ratio of 20.00 . The cost of this solution is 958 euros $/ \mathrm{m}$., which is $7.56 \%$ less than the vault designed following standard design office procedures. The standard deviation of the random results is of 37.17 euros.

Table 2: $\quad$ Summary of best vault for case study 1 .

\begin{tabular}{|l|r|}
\hline \multicolumn{2}{|c|}{ Geometric variables } \\
\hline Depth of vault & $0.200 \mathrm{~m}$ \\
\hline Depth of walls & $0.250 \mathrm{~m}$ \\
\hline Depth of slab & $0.475 \mathrm{~m}$ \\
\hline \multicolumn{2}{|c|}{ Concrete grades } \\
\hline Vault & HA-25 \\
\hline Walls & HA-25 \\
\hline Foundation & HA-25 \\
\hline \multicolumn{2}{|c|}{ Reinforcement } \\
\hline $\mathrm{A}_{1}$ & $5 \varnothing 12 / \mathrm{m}$ \\
\hline $\mathrm{A}_{2}$ & $15 \varnothing 8 / \mathrm{m}$ \\
\hline $\mathrm{A}_{3}$ & $15 \varnothing 8 / \mathrm{m}$ \\
\hline $\mathrm{A}_{4}$ & $15 \varnothing 8 / \mathrm{m}$ \\
\hline $\mathrm{A}_{7}$ & $15 \varnothing 16 / \mathrm{m}$ \\
\hline $\mathrm{A}_{8}$ & $12 \varnothing 12 / \mathrm{m}$ \\
\hline $\mathrm{A}_{13}$ & $13 \varnothing 6 / \mathrm{m}$ \\
\hline $\mathrm{A}_{17}$ & $12 \mathrm{c} \varnothing 6 / 0.33$ \\
\hline
\end{tabular}

\section{Case study 2: rectangular hollow bridge piers}

The second example studied relates hollow rectangular section RC piers used in the construction of prestressed concrete viaducts [32]. Figure 2 shows the typical pier considered in this analysis, which represents the main pier of a 60-90-60 m span viaduct over river Palancia in the motorway Valencia-Zaragoza (Castellón, Spain). The total height of the pier is $23.97 \mathrm{~m}$. The total number of variables is 95: 79 for the column and 16 for the footing. Variables for the column include 10 geometrical values for the thicknesses of the walls at different heights; 6 variables for the concrete grades; and 63 variables for the reinforcement of the column following a standard setup. As for the footing, 5 variables define the geometry and 11 the reinforcement. All variables are again discrete in this analysis. The most important parameters are the vertical height, the width and the depth of the pier of $4.84 \mathrm{~m}$ and $2.60 \mathrm{~m}$ respectively, the vertical and 
horizontal loads on the top bearings and the partial coefficients of safety. Main reactions include two vertical of $15690-11442 \mathrm{kN}$ spaced $3.60 \mathrm{~m}$ and horizontal reactions due to bearings deformations, braking and wind of $725 \mathrm{kN}, 262 \mathrm{kN}$ and $1503 \mathrm{kN}$ respectively. Structural restrictions considered followed standard provisions for these piers, except for the ULS of buckling which has been dealt with by the method of Arenas and Villegas [33].

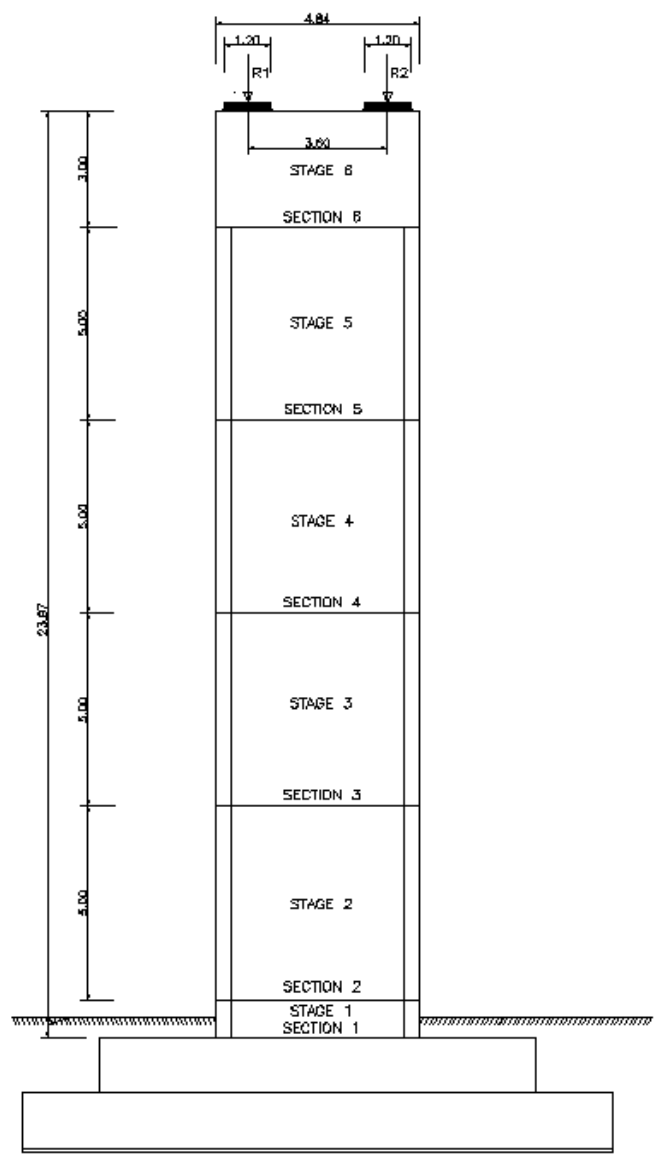

Figure 2: Typical RC rectangular hollow section pier considered for case study 2.

The TA algorithm was programmed this time in Compaq Visual Fortran Professional 6.6.0. Typical runs reduced to 168 minutes in a Pentium IV of $2.8 \mathrm{GHz}$. In this case, the calibration recommended chains of 2000 iterations, a reducing coefficient of 0.85 and $30-50 \%$ of acceptances for the initial threshold value. The most efficient move found was random variation of 14 variables of the 95 of the problem (15\% of the variables). The deviation with respect to the 
best of the random results is of $2.16 \%$. Figure 3 details the main results of the TA analysis at the cross-section at the bottom of the pier which has a concrete of class C40. The sequence of concrete grades in the 6 stages of the column is 40-40-30-25-25-25. The cost of this solution is 69367 euros. The depth of the bottom walls is 0.35 and $0.525 \mathrm{~m}$. The overall ratio of reinforcement in the hollow column is $65.20 \mathrm{~kg} / \mathrm{m}^{3}$. It may, hence, be concluded that results of the optimization search tend to slender and fairly reinforced structural piers. Results indicate savings of about $30 \%$ with respect to the design based on the experience of the bridge designers.

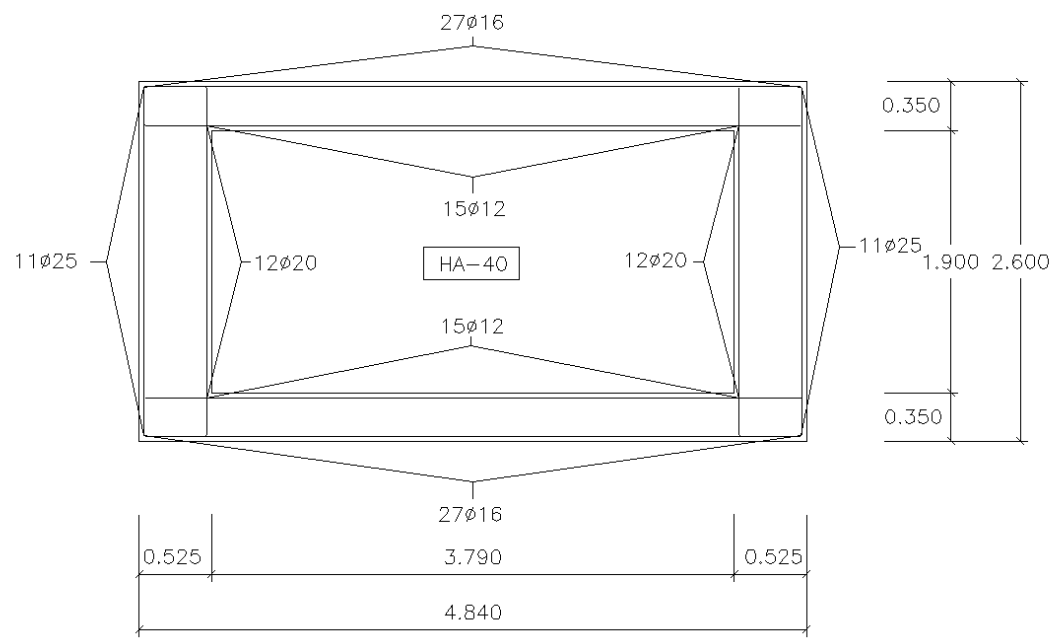

Figure 3: $\quad$ Optimized design of RC pier at bottom section.

\section{Conclusions}

From the above work, the following conclusions may be derived:

- As regards the TA procedure, it has proved an efficient search algorithm for the 2 case studies of RC vaults and hollow rectangular cross section piers used in road construction.

- Both examples presented show the potential applicability of local search heuristic procedures for the analysis of real RC structures.

\section{References}

[1] British Standards, BS 8110-1: 1997 Structural use of concrete. Part 1: Code of practice for design and construction, British Standards, London, 1997.

[2] Cohn M.Z. and Dinovitzer A.S., Application of structural optimization. ASCE Journal of Structural Engineering, 120(2), pp 617-649, 1994. 
[3] Hernández S. and Fontan A., Practical Applications of Design Optimization, WIT Press: Southampton, 2002.

[4] Fletcher R., Practical Methods of Optimization, Wiley: Chichester, 2001.

[5] Jones M.T., Artificial Intelligence Application Programming, Charles River Media: Hingham (Massachusetts), 2003.

[6] Holland J.H., Adaptation in natural and artificial systems, University of Michigan Press: Ann Arbor, 1975.

[7] Goldberg D.E., Genetic algorithms in search, optimization and machine learning, Addison-Wesley, 1989.

[8] Glover F. and Laguna M., Tabu Search, Kluwer Academic Publishers: Boston, 1997.

[9] Yepes V. and Medina J.R. Economic heuristic optimization for the heterogeneous fleet VRPHESTW. ASCE Journal of Transportation Engineering, 132(4), pp 303-311, 2006.

[10] Jenkins W.M., Plane frame optimum design environment based on genetic algorithm, ASCE Journal of Structural Engineering, 118(11), pp. 3103-3112, 1992.

[11] Rajeev S. and Krisnamoorthy C.S., Discrete optimization of structures using genetic algorithms, ASCE Journal of Structural Engineering, 118(5), pp. 1233-1250, 1992

[12] Coello C.A., Christiansen A.D. and Santos F., A simple genetic algorithm for the design of reinforced concrete beams, Engineering with Computers, 13, pp. 185-196, 1997.

[13] Rajeev S. and Krisnamoorthy C.S., Genetic algorithm-based methodology for design optimization of reinforced concrete frames, Computer-Aided Civil and Infrastructure Engineering, 13, pp 63-74, 1998.

[14] Koumousis V.K. and Arsenis S.J., Genetic algorithms in optimal design of reinforced concrete members, Computer-Aided Civil and Infrastructure Engineering, 13, pp 43-52, 1998.

[15] Hrstka O., Kucerova A., Leps M. and Zeman J., A competitive comparison of different types of evolutionary algorithms, Computers and Structures, 81, pp 1979-1990, 2003.

[16] Leps M. and Sejnoha M., New approach to optimization of reinforced concrete beams, Computers and Structures, 81, pp 1957-1966, 2003.

[17] Lee C. and Ahn J., Flexural design reinforced concrete frames by genetic algorithm, ASCE Journal of Structural Engineering, 129(6), pp 762-774, 2003.

[18] Camp C.V., Pezeshk S. and Hansson H., Flexural design reinforced concrete frames using a genetic algorithm, ASCE Journal of Structural Engineering, 129(1), pp 105-115, 2003.

[19] Sahab M.G., Ashour A.F. y Toporov V.V., Cost optimisation of reinforced concrete flat slab buildings, Engineering Structures, 27, pp 313-322, 2005.

[20] Govindaraj V. and Ramasamy J.V., Optimum detailed design of reinforced concrete continuous beams using genetic algorithms, Computers and Structures, 84, pp 34-48, 2005. 
[21] Gonzalez-Vidosa F., Yepes V., Alcala J., Carrera M. and Perea C., Simulated annealing optimization of walls, portal and box reinforced concrete road structures, In Proceedings of the Ninth International Conference on Computer Aided Optimum Design in Engineering, Skiathos (Greece), pp 175-186, 2005.

[22] Perea C., Paya I., Yepes V. and Gonzalez-Vidosa F., Heuristic optimization of reinforced concrete road bridges and frames, In Proceedings Second FIB Congress, Naples, June 2006.

[23] Paya I., Yepes V., Gonzalez-Vidosa F. and Hospitaler A., Multiobjective simulated annealing optimization of concrete building frames. In Proceedings of the IABSE Symposium on Responding to Tomorrow's Challenges in Structural Engineering, Budapest, September 2006.

[24] Perea C., Yepes V., Alcala J., Hospitaler A. and Gonzalez-Vidosa F., Heuristic optimization of reinforced concrete road bridge frames. In Proceedings of the Eighth Conference on Computational Structures Technology, Las Palmas (Spain), September 2006.

[25] Paya I., Yepes V., Clemente J. and Gonzalez-Vidosa F., Heuristic optimization of reinforced concrete building frames (in Spanish), Rev. Int. Met. Num. Calc. Dis. Ing., 22(3), pp 241-259, 2006.

[26] Dueck G. and Scheuer T. Threshold accepting: A general purpose optimization algorithm superior to simulated annealing. Journal of Computation Physics, 90, pp 161-175, 1990.

[27] Kirkpatrick S., Gelatt C.D. and Vecchi M.P., Optimization by simulated annealing, Science, 220(4598), pp. 671-680, 1983.

[28] Medina J.R., Estimation of incident and reflected waves using simulated annealing, ASCE Journal of Waterway, Port, Coastal and Ocean Engineering, 127(4), pp. 213-221, 2001.

[29] Carbonell A., Heuristic optimization of reinforced concrete road vaults (in Spanish), Research Report CST/GPRC-05, Dep. Construction Engg., Un. Politécnica Valencia, December 2005.

[30] M. Fomento, IAP-98. Code about the actions to be considered for the design of road bridges (in Spanish), M. Fomento: Madrid, 1998.

[31] M. Fomento, EHE. Code of Structural Concrete (in Spanish), M. Fomento, Madrid, 1998.

[32] Martinez F., Heuristic optimization of reinforced concrete rectangular hollow section road piers (in Spanish), Research Report CST/GPRC-08, Dep. Construction Engg., Un. Politécnica Valencia, July 2006.

[33] Arenas J.J. and Villegas L.M., Estudio de una pila esbelta en ménsula de hormigón armado, con sección y armaduras variables a lo largo de su altura, solicitadas por acciones contenidas en uno o en sus dos planos principales, Hormigón y Acero, (149), pp 15-43, 1983. 